\section{El Convenio Marco para el Control del Tabaco: un hito en la historia de la salud pública}

\author{
Mirta Roses Periago ${ }^{1}$
}

La Revista Panamericana de Salud Pública/Pan American Journal of Public Health publica en este número dos artículos sobre el tabaco y se hace eco de la aprobación del proyecto de texto del Convenio Marco para el Control del Tabaco (CMCT). De los artículos, el primero es una revisión de la literatura sobre la prevalencia del tabaquismo y sus factores de riesgo entre los adolescentes. El segundo trata de refutar las acusaciones infundadas de ciertas organizaciones al efecto de que la política de control del tabaco de la Organización Mundial de la Salud (OMS) afecta adversamente a las economías de los países y en especial a los cultivadores de tabaco. Mientras que el primero pone de manifiesto la magnitud de la epidemia del tabaquismo, que cada año mata a más de un millón de personas en la Región de las Américas, el segundo describe el clima hostil que tienen que enfrentar los profesionales y las autoridades de la salud pública para poder contrarrestar esta epidemia. Los dos artículos son relevantes porque ilustran los dos polos de un debate que ha llevado a la aprobación del proyecto de texto del $\mathrm{CMCT}$, primer tratado internacional en la historia de la salud pública.

Por primera vez, la OMS ha usado sus poderes constitucionales para negociar un tratado de salud pública, y no podría haber un mejor tema que el tabaco, pues se trata de un producto que mata a la mitad de quienes lo consumen a largo plazo, que las empresas transnacionales promueven con agresividad y que causa casi cinco millones de defunciones anuales en el mundo. El tabaquismo es, además, un problema de salud pública para el cual hay soluciones bien establecidas y sumamente económicas.

Tras cuatro años de largas e intensas deliberaciones, los delegados de la mayoría de los Estados Miembros de la OMS hacían oír sus voces en la madrugada del primero de marzo en Ginebra, Suiza, uno después de otro, en favor del proyecto de texto del CMCT, por el que muchos de ellos habían luchado tanto. A pesar de que el proyecto de texto dista de ser perfecto, el CMCT debe reconocerse como una victoria sin antecedentes en el campo de la salud pública. El texto ofrece protecciones sustantivas para la salud del público y contiene fórmulas conciliatorias destinadas a satisfacer los intereses y las capacidades de la mayoría de los Estados Miembros.

El CMCT es un magnífico punto de partida para el control mundial del tabaco y facilitará enormemente las iniciativas de control nacionales. El tratado exige a los países que lo ratifiquen que prohíban, dentro de los límites de sus constituciones, toda la promoción directa e indirecta de los productos de tabaco y que en los paquetes de dichos productos se dedique como mínimo 30\% de las superficies principales a advertencias sanitarias. El texto permite gran flexibilidad en lo que respecta a la mayoría de los temas restantes, a la vez que proporciona un marco sólido a los países para que orienten sus esfuerzos por controlar el tabaco, especialmente en relación con los impuestos sobre sus productos, la protección contra la exposición involuntaria al humo de tabaco, la puesta en práctica de medidas enérgicas contra el contrabando y la prohibición de ventas a menores. Se espera que el CMCT se complemente en el futuro con la negociación de protocolos con obligaciones sustantivas detalladas en áreas específicas.

En la sesión final de la negociación, solo tres países en total, dos de ellos en el continente americano, declararon explícitamente que no podrían firmar el tratado. La abrumadora mayoría de los países se pronunciaron en favor del mismo, y en todas las negociaciones casi todos los países americanos manifestaron su apoyo a un texto fuerte e integral con obligaciones sustantivas.

El próximo paso en el proceso será la adopción del CMCT por la 56. ${ }^{\text {a }}$ Asamblea Mundial de la Salud en mayo de 2003, después de la cual el CMCT estará abierto para la firma y ratificación por cada país. La ratificación del tratado por cuarenta Estados Miembros desencadenará su entrada en vigor.

El reto durante los próximos dos meses consisitirá en mantener el apoyo de los países al texto del CMCT en su redacción actual. Se anticipa que las empresas tabacaleras ejercerán presiones políticas para volver a abrir las negociaciones en la 56. ${ }^{\mathrm{a}}$ Asamblea Mundial de la Salud a fin de debilitar el texto o instar a los países a que voten contra su adopción. Todos aquellos interesados en defender la salud pública necesitan dar a conocer su firme convicción de que un CMCT como este es fundamental para el control del tabaco en el siglo XXI.

Los adversarios del CMCT intentarán hacer valer sus argumentos. Aunque todos han sido refutados detalladamente en otros foros, repito aquí algunos de ellos y las respuestas de la OPS: 
- $\quad$ El CMCT hurta el derecho de un país de fijar su propia política. Al contrario, el CMCT fue negociado y será aprobado y ratificado voluntariamente por los Estados soberanos. El CMCT refuerza a las políticas adoptadas en el nivel nacional.

- El tabaco es un tema de salud pública secundario en el mundo en desarrollo. Esto no es así. Las enfermedades no transmisibles producen dos tercios de todas las defunciones en América Latina y el Caribe y el consumo de tabaco causa un tercio de las defunciones por los dos grupos de enfermedades no transmisibles más importantes, que son el cáncer y los trastornos cardiovasculares. Para el año 2030, siete de cada 10 defunciones asociadas con el tabaco ocurrirán en los países en desarrollo.

- Los esfuerzos por controlar el consumo de tabaco serán perjudiciales para la economía. Esto tampoco es así. Existen muchas pruebas de que el control del tabaco impulsará las economías de la gran mayoría de los países o no surtirá ningún efecto sobre ellas. Esto es, en parte, porque cuando las personas dejan de gastar dinero en el tabaco, gastan dinero en otras cosas que son menos destructoras y que además incentivan el crecimiento de otros sectores de la economía.

- Los cultivadores de tabaco pueden llegar a perder sus ingresos. El CMCT, por el contrario, hace mención específica de ayudar a los cultivadores a que exploren otras formas de ganarse la vida. Para ello tienen mucho tiempo, ya que aun las proyecciones más optimistas sobre la reducción de la prevalencia del tabaquismo que podría obtenerse mediante la aplicación del Convenio Marco indican que la demanda de hoja de tabaco seguirá aumentando durante varios decenios como resultado del crecimiento de la población.

- Mayores impuestos sobre el tabaco reducirán los ingresos fiscales del gobierno. Es lo contrario. Los datos del mundo desarrollado y en desarrollo, en el norte y el sur, el oriente y el occidente, indican que los aumentos de los impuestos sobre el tabaco incrementan los ingresos tributarios, aunque aumente el contrabando.

- Las politicas de control del tabaco perjudican a los pobres porque les imponen cargas fiscales excesivas. Sin embargo, los que dejen de fumar se ahorrarán los costos de los daños a su salud. Los que sigan consumiendo tabaco podrían beneficiarse de programas para dejar de hacerlo o de otros programas sociales financiados con los ingresos tributarios adicionales. En cualquier caso, el efecto de un solo impuesto no se puede considerar aisladamente, ya que lo importante es que la política fiscal en su conjunto no grave más a pobres que a ricos. Los gobiernos tienen mecanismos para compensar la posible regresividad de algunos impuestos específicos y mantener la progresividad del conjunto de los impuestos.

- Los impuestos actuales sobre el tabaco compensan ampliamente los costos originados por su consumo. Los ingresos tributarios del tabaco no compensan los costos directos e indirectos del consumo de tabaco y, aunque lo hicieran, este argumento es espurio. El pago de impuestos por ciudadanos y negocios no les da derecho a causar un daño equivalente a la cantidad de los impuestos pagados.

Aunque superemos estos retos para la adopción del CMCT 56. ${ }^{\mathrm{a}}$ por la Asamblea Mundial de la Salud, hay un reto aun mayor en los próximos años: lograr que los Estados Miembros de la OMS —ratifiquen o no el CMCT — inviertan seriamente en el control del tabaco. El CMCT proporciona un marco para la acción, pero tendrá una repercusión solo si los países están dispuestos a invertir voluntad política e infraestructura a escala nacional Estas inversiones, como lo demuestran las pruebas científicas existentes, rendirán beneficios tanto de salud como económicos. Junto con las inmunizaciones, las medidas de control del tabaco se consideran las medidas sanitarias más eficaces en función de los costos.

La OPS seguirá prestando cooperación técnica para el desarrollo y la aplicación de medidas eficaces de control del tabaco, de acuerdo a la resolución CD 43/13 de su Consejo Directivo, con un apoyo cada vez mayor por parte de las agencias internacionales de ayuda al desarrollo. Según se indicó en una reciente mesa redonda de alto nivel patrocinada por la Comisión Europea sobre el control del tabaco y la política de desarrollo, los países donantes están dispuestos a apoyar económicamente el control del tabaco como parte de sus prioridades de ayuda al desarrollo, siempre y cuando los países demuestren que se comprometen a invertir recursos propios.

La adopción del CMCT será un logro importante para la OMS y creará las condiciones para el desarrollo de instrumentos jurídicos internacionales en otras áreas de la salud pública. Insto a los profesionales y a las autoridades de la salud pública en las Américas a que usen su capital político y humano para unirse en torno al CMCT y mantener esta victoria sin antecedentes en el campo de la salud pública. 